\title{
Experimental Study on Chromium Containment by Admixed Soil Liner
}

\author{
Sudipta Ghosh ${ }^{1}$; Somnath Mukherjee ${ }^{2}$; Kunal Sarkar ${ }^{3}$; Ashraf Z. Al-Hamdan, AM, ASCE ${ }^{4}$, \\ Krishna R. Reddy, M.ASCE 5
}

\begin{abstract}
Chrome tanneries generate large quantities of chromium-laden sludge which require proper disposal in engineered landfills to prevent contamination of subsurface soils and groundwater and reduce the risk to public health and the environment. This study investigates the feasibility of using a fine-grained soil as a suitable landfill liner material for the effective containment of chromium in the sludge leachate. Several series of laboratory permeability, adsorption and column tests were conducted using the soil without and with selected additives (rice husk, bentonite, and flyash) to determine permeability and adsorption and transport of chromium in the soil. Permeability tests showed that the field soil amended with $17 \%$ rice husk and $2 \%$ bentonite provides the desired hydraulic conductivity of $10^{-7} \mathrm{~cm} / \mathrm{s}$ (or less) to minimize the leachate migration into the surrounding subsurface environment. The rice husk and bentonite admixtures significantly reduced the permeability of the soil from $3 \times 10^{-7}$ to $2.8 \times 10^{-9} \mathrm{~cm} / \mathrm{s}$, and this admixture was further tested for its effect on the adsorption and transport of chromium in the
\end{abstract}

\footnotetext{
${ }^{1}$ Professor, Department of Civil Engineering, Jadavpur University, Kolkata-700032, India. E-mail: sghosh56@yahoo.com

${ }^{2}$ Professor, Department of Civil Engineering, Jadavpur University, Kolkata-700032, India. E-mail: snm_ju@yahoo.co.in

${ }^{3}$ Post-Graduate Student, Department of Civil Engineering, Jadavpur University, Kolkata-700032, India. E-mail: kunalinkolkatta@yahoo.co.in

${ }^{4}$ Lecturer, Dept. of Civil and Environmental Engineering, Univ. of Alabama in Huntsville, 301 Sparkman Drive, Huntsville, Alabama 35899, USA (corresponding author). E-mail: alhamdan@eng.uah.edu

${ }^{5}$ Professor, Dept. of Civil and Materials Engineering, Univ. of Illinois at Chicago, 842 West Taylor Street, Chicago, Illinois 60607, USA. E-mail: kreddy@uic.edu
} 
soil. The batch kinetics and column tests results showed that the soil possess relatively high chromium adsorption capacity under natural or slightly alkaline condition. The batch tests showed the amendment marginally improved the chromium adsorptive capacity of the soil. The column tests showed slight increase in breakthrough time due to the presence of amendment. The inclined base column tests showed that a mildly inclined liner configuration has a marginal effect on the chromium attenuation in the soil. Overall, this study showed that the soil amended with $17 \%$ rice husk and $2 \%$ bentonite decreased the permeability of the soil significantly and slightly increased the adsorption of chromium; therefore, has the potential for usage as a landfill liner in landfill system to contain chromium contamination.

CE Database subject headings: Landfill; Leachate; Chromium; Clay liner; Rice husk; Adsorption; Contaminant breakthrough. 


\section{Introduction}

Chromium is considered to be a toxic heavy metal emanated from various industries such as metallurgical, refractory, chemical pigments, electroplating and tanning along with liquid or solid waste. The Chrome tanning industry is one of the large contributors of chromium pollution in land and water environment (Sarkar 1981; Apte et al. 2005; Leghouchi et al. 2009). One of the major environmental problems of tanning industry is the generation of chromium laden chemical sludge as a by product of tannery process. Since scientific solid waste disposal practices are seldom followed in India, large amount of chromium contaminated sludge is usually dumped improperly as uncontrolled topping method. The fate of chromium in such disposal sites is a cause of concern due to leaching effect under favorable condition. To contain such uncontrolled release and migration of hazardous contaminants into the environment, engineered waste landfills with liner systems consisting of low permeable materials (less than $10^{-7} \mathrm{~cm} / \mathrm{s}$ ) need to be implemented (Benson et al. 1994; Sharma and Reddy 2004). A major constraint to the development of engineered landfills in West Bengal, India is the high cost of synthetic liners and its scarcity in the local markets, thus there is a need for other readily available local source materials for landfill liners preferably soils of clayey origin.

Chromium in sludge potentially exists in the trivalent $\left(\mathrm{Cr}^{3+}\right)$ or hexavalent $\left(\mathrm{Cr}^{6+}\right)$ states under natural condition. $\mathrm{Cr}^{6+}$ is highly toxic and a human mutagenic but $\mathrm{Cr}^{3+}$ is much less toxic than $\mathrm{Cr}^{6+}$. The published literature entails that clay can be used as a liner material for containment of heavy metals generated in leachates. The migration of heavy metals through soil liners, especially clay liners, is significantly affected by the permeability (hydraulic conductivity), and cation exchange and adsorption capacity of the soil (Sharma and Reddy 2004; Rajasekaran et al. 2005; Vaishya et al. 2008). Moreover, $\mathrm{Cr}^{6+}$ reduction in soils can take place owing to surface 
chemical reactions. $\mathrm{Cr}^{6+}$ adsorption also occurs on the surfaces of aluminum oxides and amorphous iron oxides present in soils. Soil composition (electron donor availability, soil texture, competing ions, adsorption capabilities, etc.) and conditions in the soil ( $\mathrm{pH}$, moisture content, temperature, and the presence of vegetation) are the various factors affecting adsorption, leachability and mobility of chromium in soils (Zachara et al. 1989; Hanson et al. 1993; James 1994; Chen and Hao 1996). Few guidelines have been compiled for selecting appropriate soil properties and compaction methods resulting in low hydraulic conductivity (Gordon et al. 1984; Daniel et al. 1990). Some researchers have found that natural reductants such as $\mathrm{Fe}$, and organic matter present in the soil can transform $\mathrm{Cr}^{6+}$ to less toxic $\mathrm{Cr}^{3+}$ thereby resulting in natural attenuation capacity of clay (Blowes et al. 1997; Jardine et al 1999; Kozuh et al. 2000). Furthermore, it is reported that considerable chromium reduction in soils can be achieved by the use of admixtures like rice husk, fly ash and bentonite (Hu et al. 2004). In this context, it is important to understand heavy metals migration through soil liners by defining the physical and chemical properties of the leachate-soil system. Moreover, a good understanding of the migration of leachate through the soil will also facilitate the rational design of an effective amended soil liner system for landfills. However, very few studies have been carried out to assess the performance of clay liner for reduction of chromium pollution through fine grained soil (Avudainayagam et al. 2006).

The present study assesses the potential use of a local fine-grained clayey soil obtained from a site in West Bengal, India, as a landfill liner to prevent sludge leachate containing chromium from contaminating the subsurface environment. Physical and chemical tests were performed to characterize the soil. The field soil was amended with admixtures to improve its properties. 
Batch adsorption and breakthrough column tests were also conducted to evaluate the adsorption affinity and attenuation capacity of the field and amended soils for chromium.

\section{Materials and Methods}

\section{Leachate Characteristics}

Sludge samples collected from a leather tannery plant in Kolkata district of West Bengal, India, were used to assess leachate quality in this study. The total concentrations of the heavy metals in the sludge were determined using an atomic absorption spectrophotometer in accordance to the USEPA methods (USEPA 1986). Table 1 shows the heavy metals concentrations found in the tested sludge. The concentration of chromium was found to be very high compared to the other heavy metals, exceeding the permissible limit. Thus, in the present study, chromium was selected as the contaminant of major concern and the focus was made on this particular heavy metal.

\section{Soil Characterization}

A clayey soil obtained from a site close to the leather tannery plant site in around Kolkata district of West Bengal, India was used in this study. The soil was collected from $2 \mathrm{~m}$ below the ground surface. The soil was characterized by performing variety of physical and chemical tests. ASTM standard procedures were used to determine the physical properties of the soil, including density (ASTM D 2937), particle size distribution (ASTM D 422), Atterberg limits (ASTM D 4318), permeability (ASTM D 5084), and maximum dry density and optimum moisture content (ASTM D 698). The cation exchange capacity (CEC) of the soil was determined using the Ag-Tu method (ASTM D 9081). In addition, the point of zero charge ( $\mathrm{pH}_{\mathrm{PZC}}$ ) of the soil (i.e., $\mathrm{pH}$ at which the 
net surface charge is equal to zero) was determined by conducting potentiometric (titration) batch tests (Al-Hamdan and Reddy 2005). The dielectric constant of soil was estimated at $1 \mathrm{MHz}$ frequency (Carrier and Soga 1997). The dielectric constant of soil is an indication property by which the extent of ions in soil can be approximated. As the ionic strength of the pore fluid increases, the dielectric constant of the soil decreases (i.e., the dielectric constant of pure water is 80).

In addition, amended soil was prepared by mixing the field soil with selected admixtures. The admixtures were added to the soil in order to lower the soil permeability to an acceptable level (i.e., $k \leq 10^{-7} \mathrm{~cm} / \mathrm{s}$ ) (Benson et al. 1994). Three admixtures, rice husk, bentonite and flyash, were used in this study. The rice husk was obtained from a rice mill near Kolkata, India. The husk was thoroughly washed with water to remove all dirt and then oven dried at $105^{\circ} \mathrm{C}$ temperature for 24 hours. In order to optimize the admixture fractions in the field soil (i.e., to obtain permeability less than $10^{-7} \mathrm{~cm} / \mathrm{s}$ ), three permeability tests were performed on the soil mixed with each of the selected admixtures. The permeability tests for the amended soils were performed in a rigid-wall permeameter according to the falling head testing method ASTM D 5084.

\section{Batch Adsorption Tests}

Two batch adsorption tests series were performed to determine the adsorption behavior of the tested soils for chromium. In the first series, the soil was used without admixtures. In the second series, the same soil was mixed with rice husk and bentonite. Those admixtures were found effective in reducing the permeability of the soil used. The fractions by dry weight of rice husk and bentonite in the soil in the second test series were $17 \%$ and $2 \%$, respectively. In each test 
series, the USEPA batch-type test procedure was followed to determine the adsorption behavior of the tested soil for chromium (USEPA 1992). The batch adsorption experiments for the soil were conducted for five different soil to solution ratios $(3: 10,4: 10,5: 10,6: 10$, and 7:10 (mass/volume)) with a constant solution volume $(100 \mathrm{~mL})$ and two different initial concentrations of chromium ( 2 and $3 \mathrm{mg} / \mathrm{L}$ ). The source of the hexavalent chromium used in the batch tests was potassium dichromate $\left(\mathrm{K}_{2} \mathrm{CrO}_{4}\right.$, ACS certified). All adsorption tests were performed for six different contact times: 30, 60, 90, 120, 150, and 180 minutes. In each test, samples were shaken at room temperature $\left(22^{\circ} \mathrm{C}\right)$ then centrifuged at $3500 \mathrm{rpm}$ for $20 \mathrm{~min}$ and filtered using Wattman filter paper. The chromium concentration in the supernatant was determined using an Atomic Absorption Spectrophotometer (AAS). Then, the percentages of chromium removed by the soil in all tests were calculated. The minimum time after which there was no increase in the adsorption rate of chromium was taken as the equilibrium time, and the concentration of chromium remaining at that time in the supernatant is called equilibrium concentration. The amount of chromium adsorbed per unit mass of dry soil was then determined by:

$$
\frac{x}{m}=\frac{C_{o}-C_{e q}}{m} V
$$

where: $x / m=$ amount of chromium adsorbed per unit mass of dry soil, $C_{o}=$ initial chromium concentration before exposure to soil, $C_{e q}=$ chromium concentration after exposure to soil at equilibrium, and $V=$ volume of metal solution added to the reaction container.

\section{Column Breakthrough Experiments}

Two column experiments were carried out to determine the breakthrough chromium concentrations of the tested soil when permeated with chromium. In the first experiment, the soil 
was used without admixtures. In the second experiment, the soil was mixed with $17 \%$ rice husk and $2 \%$ bentonite. In each experiment, a burette column made of glass was used (Fig. 1). The column had an inside diameter of $115 \mathrm{~mm}$ and a total length of $750 \mathrm{~mm}$. In order to mimic the field density (i.e., $90 \%$ relative compaction), the tested soil was placed in the column and compacted in layers. The soils water contents at compaction were $26 \%$ and $35 \%$ for the soil with and without amendments, respectively. After compaction, the compacted soil was $550 \mathrm{~mm}$ thick. Below the compacted soil layers, three consecutive layers of filter paper, glass wool and glass bead were placed as supporting medium. The compacted soil column was permeated initially with distilled water in order to achieve the first exposure effect (Gleason et al. 1997). Then, potassium dichromate $\left(\mathrm{K}_{2} \mathrm{CrO}_{4}\right.$, ACS certified) solution was used to simulate the chromium in sludge leachate with a concentration of $7.5 \mathrm{mg} / \mathrm{L}$. The solution was allowed to vertically pass through the soil at a steady rate of $0.27 \mathrm{~mL} / \mathrm{min}$. Effluent was periodically collected. The concentration of chromium in the effluent solution was determined using AAS (Model No: Varian 50 Bio).

In addition, two series of large scale column tests were performed to obtain the breakthrough curves of chromium through the soil by evaluating time concentration parameters. In each test, an aluminum tank of $600 \mathrm{~mm}$ in diameter and $900 \mathrm{~mm}$ in height was used (Fig. 2(a)). In each test series, three experiments were performed using three different soil layer thicknesses of 100, 200, and $300 \mathrm{~mm}$, respectively. In the first series of tests, the soil used was without admixtures, while, the soil was mixed with $17 \%$ rice husk and $2 \%$ bentonite in the tests of the second series. As per EPA minimum technology guidance for hazardous waste, slopes in landfills liners should be provided. Kmet et al. (1981) showed that slopes up to $2 \%$ improve landfills performance with respect to better drainage into leachate collection and removal system. 
Therefore, in order to investigate the effect of soil liner inclination on chromium attenuation in the soil, additional two large scale column tests were performed in this study using the soil without admixtures for two different configurations. In the first test, the soil was placed without a slope at the bottom of column in a thickness of $100 \mathrm{~mm}$. While in the second test, the soil was placed in a slope of $1 \%$ using a prefabricated perforated template as seen in Fig. 2(b). The

relative compaction of the soil in all tests was $90 \%$ with respect to standard proctor density. The soil was saturated with distilled water for 24 hours before conducting the test. In all large scale tests, potassium dichromate solution was used as the source of $\mathrm{Cr}$ of initial concentration of 7.5 $\mathrm{mg} / \mathrm{L}$. The solution was allowed to pass vertically through the soil at a steady flow of 2.7 $\mathrm{mL} / \mathrm{min}$. Effluent leachate samples were periodically collected at the bottom of the soil column. The concentration of chromium in the effluent solution was determined using AAS.

\section{Results and Discussions}

\section{Soil Properties}

The physico-chemical properties of the tested clayey soil are shown in Table 2. The grain size distribution and Atterberg limits results show that the soil is classified as medium plasticity clay (CL) according to the Unified Soil Classification System, indicating the potential of the soil for use as a liner to control or restrict the migration of leachate into the subsurface environment (Benson et al. 1999). Moreover, the soil exhibited a low cation exchange capacity of 1.9 meq/100 g. The low cation exchange capacity of the soil may limit the replacement of the adsorbed metals by other ions exist in the pore water. Thus, adsorption phenomenon becomes predominant for the attenuation mechanism of hexavalent chromium. 
Using the falling head test, the soil hydraulic conductivity is found to be relatively low $\left(2.7 \times 10^{-7} \mathrm{~cm} / \mathrm{sec}\right)$. The soil hydraulic conductivity can be further reduced by using proper compaction or admixtures to achieve the desired permeability for landfill liners as suggested by Benson et al. (1994) (i.e., $k \leq 10^{-7} \mathrm{~cm} / \mathrm{s}$ ). Benson et al. (1999) developed a correlation between the geometric mean hydraulic conductivity and the soil compaction condition through the average wetness and scattering value relative to the line of optimum of the compaction curve $\left(P_{o}\right)$. Benson et al. (1999) defines $P_{o}$ as the ratio of number of $\left(w, \gamma_{\mathrm{d}}\right)$ points above line of optimum to the total number of $\left(w, \gamma_{\mathrm{d}}\right)$ points measurements, where, $w$ is the water content after compaction and $\gamma_{\mathrm{d}}$ is the compacted soil dry unit weight. Soils with high $P_{o}$ percentages have the potential to achieve the desired permeability for landfill liners. In this study, compaction tests were performed and the maximum dry density and optimum moisture content were determined using the Standard Proctor (ASTM D698), Modified Proctor (ASTM D1557), and Reduced Standard Proctor compaction methods. The Reduced Proctor method involved using 15 blows of the hammer per layer instead of 25 blows normally used in the Standard Proctor test. The $P_{o}$ percentages for the tested soil were about $70 \%$ and $67 \%$ for the modified and standard Proctor compaction methods, respectively. Therefore, the soil possesses the potential to achieve the desired permeability for landfill liners $\left(\leq 1 \times 10^{-7} \mathrm{~cm} / \mathrm{s}\right)$ and adequate strength under compaction. Moreover, the maximum dry unit weights of the soil under the standard and modified Proctor compaction efforts were, respectively, $16.8 \mathrm{kN} / \mathrm{m}^{3}$ and $17.2 \mathrm{kN} / \mathrm{m}^{3}$, indicating that the soil possesses high strength and resistance to damage (Blotz et al. 1998).

The falling head permeability tests (ASTM D 5086) results for the field soil mixed with rice husk, bentonite, and fly ash are depicted in Fig. 3. Fig. 3 shows that the soil permeability decreases considerably as the admixture fraction (by dry weight) of rice hulk and bentonite 
increases. The optimum admixtures weight fractions mixed with the soil were $17 \%$ and $2 \%$ for rice husk and bentonite, respectively. These optimum fractions of admixtures considerably lowered the soil permeability from $10^{-7}$ to $10^{-9} \mathrm{~cm} / \mathrm{s}$. When mixed with soil, bentonite reduces the soil permeability because of its high plasticity index $(\mathrm{LL}=290 \%, \mathrm{PL}=30 \%)$, small particles, and thick double layer (Mesri and Olson 1971). On the other hand, rice husk contains 15-20\% silica $\left(\mathrm{SiO}_{2}\right)$ which contributes to its hard and abrasive protective casing covering the rice grain and soil and subsequently filling the soil voids and leading to reduced permeability values. The permeability results suggests that an amended soil made from the local site soil mixed with $17 \%$ rice husk and and $2 \%$ bentonite would have the potential for usage as a landfill liner to prevent leachate transmission to groundwater.

\section{Batch Adsorption Results}

Fig. 4 shows the batch kinetics profiles of chromium adsorption by both tested soils (i.e., with and without admixtures) for different soil to solution ratios. As the soil to solution ratio in the suspension increases, the amount of the chromium adsorbed to the soil increases. This could be attributed to the increase in the available adsorption sites. The kinetic profiles also show that approximately $40-80 \%$ of chromium adsorption occurred within a contact time of 90 minutes; thereafter the rate of chromium adsorption by the soil was noticeably decreased. This could be attributed to the significant reduction in the available adsorption sites of the soil. Fig. 4 also suggests that the presence of admixtures in soil increased the adsorption of chromium to the soil. When the soil contained no admixtures, the percent removal of chromium after 90 minutes of contact time was between $70-80 \%$, while it increased to $90-92 \%$ when the soil was mixed with $17 \%$ rice husk and $2 \%$ bentonite. The addition of bentonite to the soil increases its clay content, 
increasing the available adsorption sites for chromium. Furthermore, as shown in the Fig. 5, the $\mathrm{pH}$ and electrical conductivity of the suspension decreases as the clay content in the solution increases (i.e., $\mathrm{H}^{+}$ions released into the solution). The adsorption affinity of anions (hexavalent chromium) to the soil surfaces increases in an acidic environment $(\mathrm{pH}<7)$ (Al-Hamdan and Reddy 2005). However, the use bentonite and rice husk with soil marginally improved the sorption capacity of soil because of relatively high initial $\mathrm{pH}$ condition of the soil $(\mathrm{pH}=7.64)$; limiting the effect of admixtures on the uptake adsorption capacity of soil. These results also confirm the findings of Guo et al. (2002). Moreover, the adsorbed chromium in the presence of rice husk is in organic form that is represented by $\mathrm{Cr}_{3}(\mathrm{OH})_{2}\left(\mathrm{OOCCH}_{3}\right)_{7}$. This chromium is considered to link with the rice husk through $-\mathrm{COO}$ and $-\mathrm{O}^{-}$groups via weak ionic exchange with a proton (Hu et al. 2004). The scanning electron microscope (SEM) morphology of the soil before and after chromium sorption with and without rice husk is shown in Fig. 6. The SEM images suggest that the surface structure of soil has disintegrated after $\mathrm{Cr}^{6+}$ adsorption. This may be attributed to the considerable oxidation capability of $\mathrm{Cr}^{6+}$ towards soil. Due to such disintegration perhaps more pore spaces are available for adsorption of $\mathrm{Cr}^{6+}$. When rice husk is added with soil (Fig. 6(c)), further coalescences of soil particles appear to take place. Rice husk reinforces the soil structure, preventing further disintegration. Therefore, soil particles did not loosen due to addition of rice husk, resulting adsorption of $\mathrm{Cr}^{6+}$ for this amendment enhanced. The chromium adsorption isotherm of the soil was obtained from the batch adsorption experimental results, expressed in the relationship between the amount of chromium adsorbed per unit mass of dry soil and the equilibrium concentration of chromium. In literature, there are various isotherm equations ranging almost fully empirical to largely theoretical (Cheng et al. 2004). Among them, the simplest isotherm is the Langmuir model which applies to uniform 
surfaces. The Freundlich isotherm is probably the most commonly used isotherm when the surface is not energetically uniform (Cheng et al. 2004). The Freundlich isotherm is given by:

$$
\frac{x}{m}=K_{F} C_{e q}^{1 / n}
$$

where $x / m$ is the amount of chromium adsorbed per unit mass of dry soil, $\mathrm{x}$ is the amount of solute adsorbed by the soil in $\mathrm{gm}, \mathrm{m}$ is the amount of soil in the reactor in $\mathrm{gm}, K_{F}$ is Freundlich adsorption constant, $1 / n$ is Freundlich exponent constant, and $C_{e q}$ is the chromium concentration in solution at equilibrium $(\mathrm{mg} / \mathrm{L})$. While, the Langmuir isotherm is given by:

$$
\frac{x}{m}=\frac{\alpha \beta C_{e q}}{1+\alpha C_{e q}}
$$

where $\alpha$ is the adsorption constant related to the binding energy $(\mathrm{L} / \mathrm{mg}), \beta$ is the maximum amount of solute that can be adsorbed by the soil $(\mathrm{mg} / \mathrm{kg})$, and $C_{e q}$ is the chromium concentration in solution at equilibrium $(\mathrm{mg} / \mathrm{L})$.

In this study, Freundlich and Langmuir adsorption models were fitted to the test results as shown in Fig. 7. The relevant isotherm parameters of Freundlich model are $\left(K_{F}=4.80 \mathrm{~L} / \mathrm{g}, 1 / n=\right.$ $0.269)$ and $\left(K_{F}=4.04 \mathrm{~L} / \mathrm{g}, 1 / n=0.472\right)$ for the soil without and with admixtures, respectively. The Freundlich constant $1 / n$ corresponds to adsorption intensity. The low value of $1 / n$ in Freundlich model implicates that the retardation factor $(R)$ is relatively low and the soil has relatively low chromium attenuation capacity (Agarwal et al. 2002). However, the presence of rice husk and bentonite in the soil slightly improved the chromium adsorption intensity. In addition, the Langmuir model parameters are $(\alpha=185 \mathrm{~L} / \mathrm{mg}, \beta=5.33 \mathrm{mg} / \mathrm{kg})$ and $(\alpha=69.7$ $\mathrm{L} / \mathrm{mg}, \beta=6.15 \mathrm{mg} / \mathrm{kg}$ ) for the soil without and with admixtures, respectively. Hence, the maximum amount of chromium can be adsorbed by the soil without and with admixtures are, respectively, 5.33 and $6.15 \mathrm{mg} / \mathrm{kg}$, indicating that the soil with and without amendment has 
relatively low chromium adsorption capacity at natural $\mathrm{pH}$ condition (i.e., $\mathrm{pH}=7.8>\mathrm{pH}_{\mathrm{PZC}}=$ 7.3). In addition, the presence of rice husk and bentonite in the soil slightly improved its adsorption capacity. However, at natural and slightly alkaline conditions, the low adsorption capacity of the soil for the anion hexavalent chromium may be considered significant as $\mathrm{pH}$ of the system is greater than the soil $\mathrm{pH}_{\mathrm{PZC}}$. Hence, the adsorption and attenuation capacity of the test soil for the chromium increases as the system $\mathrm{pH}$ decreases to lower levels less than the soil $\mathrm{pH}$ PZC.

\section{Contaminant Breakthrough Curves}

Fig. 8 shows the chromium breakthrough curves in the column tests for both soils (with and without admixtures). In the soil without admixtures, the initial breakthrough was observed after 600 hours. The equilibrium concentration reached after 900 hours at which approximately $93 \%$ of the initial concentration had been traced in the effluent solution, which indicated exhaustion of the soil column. Fig. 8(b) shows the breakthrough of chromium in the amended soil column. Fig. 8 demonstrates that the addition of admixtures in the soil changed the contaminant breakthrough from 600 to 750 hours $\left(C / C_{0}=0.95\right)$. The equilibrium concentration reached after 950 hours at which approximately $99 \%$ of the initial concentration had been traced in the effluent solution.

Fig. 9 shows the chromium breakthrough curves in the large tank tests for both soils (with and without admixtures). In the soil without admixtures and for the three soil thicknesses (Fig.9a), the breakthrough for $\mathrm{C} / \mathrm{C}_{0}=0.5$ was observed at about 175 hours. The equilibrium concentration reached after 900 hours at which approximately $90 \%$ of the initial concentration had been traced in the effluent solution, which indicated exhaustion of the soil column. Fig. 9(b) shows the breakthrough of chromium in the amended soil column and it demonstrates that the 
addition of admixtures in the soil retarded the contaminant breakthrough at relative concentration of $50 \%\left(\mathrm{C} / \mathrm{C}_{0}=0.5\right)$ to about 360,435 and 580 hours for the tests with the soil thicknesses of 100,200 and $300 \mathrm{~mm}$, respectively. The addition of admixture was also found to retard the equilibrium concentration in all the three cases to after 950 hours.

Fig. 10 shows the chromium breakthrough curves for field soil without amendment as obtained from the large scale tank tests for both cases (i.e., with and without slope at the bottom of the soil). Fig. 10 exhibits the variation of concentration ratio (i.e., $\mathrm{C} / \mathrm{C}_{0}$ ) with time for an input chromium concentration of $7.5 \mathrm{mg} / \mathrm{L}$ and a soil thickness of $100 \mathrm{~mm}$. Without a slope at the bottom of soil layer, the initial breakthrough was observed after 175 hours when $50 \%$ of initial concentration was found in the effluent. The equilibrium concentration reached after 900 hours at which approximately $98 \%$ of the initial concentration was traced in the effluent solution. When a mild slope was provided at the bottom of the soil column, the breakthrough occurred earlier than the case where there was no slope at the bottom. The mild slope helped the leaching solution for draining to the effluent point faster. Fig. 10 shows that the effect of slope on leachate behavior is marginal. This observation is similar to the results of a study done by Drury (1997).

\section{Conclusions}

The study investigated the potential usage of a fine-grained clayey soil with and without amendment (mixed with $17 \%$ rice husk and $2 \%$ bentonite) as a liner material to contain chrome tanning waste sludge in India. Physical-chemical characterization tests and batch and column experiments were conducted for the soil before and after amendment. Based on this study, the following conclusions can be drawn: 
1. The field soil is a clayey soil, with the potential to meet the basic engineering properties for clay liners in terms of the required hydraulic conductivity and adsorption capacity. The field soil possesses a low permeability that is slightly higher than the required value; however, the soil permeability can be further reduced by using admixtures. The soil permeability was substantially reduced from $3 \times 10^{-7}$ to $2.8 \times 10^{-9} \mathrm{~cm} / \mathrm{s}$ when it was mixed with $17 \%$ rice husk and $2 \%$ bentonite.

2. The mechanism of chromium attenuation was primarily due to adsorption by the soil as indicated by the adsorption studies. The batch kinetics tests results showed that the soil possesses relatively a good chromium adsorption capacity at natural or slightly alkaline condition. The presence of $17 \%$ rice husk and $2 \%$ bentonite in the soil marginally enhanced its adsorption capacity.

3. The addition of admixtures in the soil columns slightly increased the chromium attenuation. The initial chromium breakthrough in the soil column was changed from $600 \mathrm{~h}$ to $900 \mathrm{~h}$ for different soil thicknesses when $17 \%$ rice husk and $2 \%$ bentonite was mixed with the soil. The chromium breakthrough curves reached equilibrium concentration after $900 \mathrm{~h}$ for the field soil and $1000 \mathrm{~h}$ when the soil was amended the admixtures.

4. Placing the field soil liner in a mildly inclined configuration has marginal effect on the chromium breakthrough.

Overall, this study showed that the amended soil has the potential for usage as a low permeability landfill liner or as a component of a landfill barrier system to contain chromium leachate. The positive environmental implication of this study lies in the fact that there is a high prospect of utilization of local clayey soils as low-cost landfill liner materials. 


\section{References}

Agarwal, I. C., Srivastava, R. K, and Agarwal, A. (2002). "Sorption mechanism of arsenic on two soils of Northern India." Proc., $4^{\text {th }}$ International Congress on Environmental Geotechnics, Netherlands, 141-144.

Al-Hamdan, A. Z., and Reddy, K. R. (2005). "Surface speciation modeling of heavy metals in kaolin: implications for electrokinetic soil remediation processes." Adsorption, 11, 529546.

Apte, A. D., Verma, S., Tare, V. and Bose, P. (2005) “Oxidation of Cr (III) in tannery sludge to Cr (VI): Field observations and theoretical assessment.” J. Hazard. Mater., B121, 215222.

Benson, C., Zhai, H. and Wang, X. (1994). "Estimating hydraulic conductivity of compacted clay liners." J. Geotech. Eng., 120(2), 366-387.

Benson, C.H., Daniel, D. E., and Boutwell, G. P. (1999). "Field performance of compacted clay liners." J. Geotech. Geoenviron. Eng., 125(5), 390-402.

Blowes, D. W., Ptacek, C. J., and Jambor, J. L. (1997). "In-situ remediation of Cr (VI)contaminated groundwater using permeable reactive walls: Laboratory studies." Environ. Sci. Technol., 31(12), 3348-3357.

Boltz, L. R., Benson, C.H, and Boutwell, G. P., (1998) "Estimating optimum water content and maximum dry unit weight for compacted clays.” J. Geotech. Geoenviron. Eng. 124(9), 907-912.

BIS (1997), Bureau of Indian Standards, New Delhi, India.

Carrier, M., and Soga, K. (1999). "A four terminal measurement system for measuring the dielectric properties of clay at low frequencies." Eng. Geology, 53(2), 115-123. 
Chen, J. M., and Hao, O. J. (1996). "Environmental factors and modeling in microbial chromium (VI) reduction." Water Environ. Res., 68(7), 1156-1164.

Cheng, T., Jiang, Y., Zhang, Y., and Liu, S. (2004) "Prediction of breakthrough curves for adsorption on activated carbon fibers in a fixed bed." Carbon, 42, 3081-3085.

Daniel, D. E., and Benson, C. H. (1990). "Water content density criteria for compacted soil liners." J. Geotech. Eng., 116(12), 1811-1830.

Drury, D. (1997). "Hydraulic considerations for choice of landfill liner." Proc., Conference Organized by British Geotechnical Society and Cardiff School of Engineering, University of Wales, Cardiff $16-18^{\text {th }}$ September, 312-318.

Gleason, M., Daniel, D., and Eykholt, G. (1997). "Calcium and sodium bentonite for hydraulic containment applications." J. Geotech. Geoenviron. Eng., 123, 438-445.

Gordon, M. E., Huebner, P. M., and Kmet, P. (1984). “An evaluation of the performance of four clay lined landfills in Wisconsin." Proc., Seventh Annual Madison Waste Conference., Univ. of Wisconsin, Madison, Wisconson, 399-460.

Guo, Y., Qi, J ., Yang, S., Yu, K., Wang, Z., and Xu, H. (2002). “Adsorption of $\mathrm{Cr}^{6+}$ on microand mesoporous rice husk-based active carbon." J. Mater. Chem. Physics, 78(1), 132137.

Hanson, A. T., Dwyer, B. D., Samani, Z. A., and York, D. (1993). "Remediation of chromium containing soils by heap leaching: a column study." J. Environ. Eng., 119, 824-841.

Hu, M. J., Wei, Y. L, Yang, Y. W., and Lee, J. F. (2004). "X-Ray adsorption spectroscopy study of chromium recovered from $\mathrm{Cr}^{6+}$ containing water with rice husk." J. Physics: condens. Matter, 16(33), S3473-S3478. 
James, B. R. (1994). "Hexavalent chromium solubility and reduction in alkaline soils enriched with chromate ore processing residue.” J. Environ. Qual., 23, 227-233.

Jardine P. M., Fendorf, S. E., Mayes, M. A., Larsen, I. L., Brooks, S. E., and Bailey W. B. (1999) "Fate and transport of hexavalent chromium in undisturbed heterogeneous soil." Environ. Sci. Technol., 33(17), 2939-2944.

Kmet, P., Quinn, K. J., and Slavic, C. (1981). "Analysis and design parameters affecting collection efficiency of clay lined landfills." $4^{\text {th }}$ Annual Madison Conference of Applied Research and Practice on municipal and industrial waste, 28-30.

Kozuh, N., Stuper, J., and Gorenc, B. (2000). "Reduction and oxidation processes of chromium in soils.” Environ. Sci. Technol., 34, 112-119.

Leghouchi, E, Laib, E Guerbet, M (2009) "Evaluation of Chromium contamination in water, sediment and vegetation caused by the tannery of Jijel (Algeria) - A case study." Environ. Monitor. Assess., 153, 111-117.

Mesri, G., and Olson, R.E. (1971). "Mechanisms Controlling the Permeability of Clays.” Clays and Clay Minerals, 19(3), 151-158.

Rajasekaran, G., Murali, K., Nagan, S., Amoudhavally, V., and Santhaswaruban, V. (2005) “Contaminant transport modeling in marine clays.” Ocean Eng., 32, 175-194.

Sarkar, K. T. (1981). Theory and Practice of Leather Manufacturing, Ajay Sorcar, Madras, Inida

Sharma, H. D., and Reddy, K. R. (2004). Geoenvironmental Engineering: Site Remediation, Waste Containment, and Emerging Waste Management Technologies, John Wiley \& Sons, Hoboken, New Jersey.

Vaishya, R. C., Sethy, M. M., and Reddy, K. R. (2008). “A new reactive barrier material for use in landfill liners and in Situ barriers to immobilize chromium." Proc., 6th International 
Groundwater Quality Conference, Fremantle, Western Australia, IAHS Publication 324, 273-280.

U.S. Environmental Protection Agency (USEPA) (1986). Test Methods for Evaluating Solid Waste, third ed., vol. 1A. Laboratory Manual, Physical/Chemical Methods. SW-846, Office of Solid Waste and Emergency Response, Washington, DC.

U.S. Environmental Protection Agency (USEPA) (1992). Batch-type procedures for estimating soil adsorption of chemicals, EPA/530/SW-87/006-F, Office of Solid Waste and Emergency Response, Washington, DC.

Zachara, J. M., Ainsworth, C. C., Cowan, C. E., and Resch C. T. (1989). "Adsorption of chromate by subsurface soil horizons." Soil Sci. Soc. Am. J., 53, 418-428. 
Table 1. Heavy metals found in the sludge from tannery

\begin{tabular}{cc}
\hline Metal & $\begin{array}{c}\text { Concentration } \\
(\mathrm{gm} / \mathrm{kg})\end{array}$ \\
\hline $\mathrm{Cr}$ & 14 \\
$\mathrm{Fe}$ & 0.70 \\
$\mathrm{Mn}$ & 0.58 \\
$\mathrm{Mg}$ & 1.83 \\
$\mathrm{Zn}$ & 0.24 \\
$\mathrm{Ni}$ & 0.27 \\
$\mathrm{~Pb}$ & 0.06 \\
$\mathrm{Cd}$ & Not Detected \\
$\mathrm{Cu}$ & Not Detected \\
\hline
\end{tabular}


Table 2. The physico-chemical properties of the tested soil

Property

\begin{tabular}{|c|c|c|}
\hline \multicolumn{2}{|l|}{ Bulk density $\left(\mathrm{kN} / \mathrm{m}^{3}\right)$} & 18.3 \\
\hline \multicolumn{2}{|c|}{ Optimum moisture content $(\%)$} & 17.20 \\
\hline \multicolumn{2}{|c|}{ Maximum dry density $\left(\mathrm{kN} / \mathrm{m}^{3}\right)$} & 16.80 \\
\hline \multicolumn{2}{|c|}{ In-Situ Water content $(\%)$} & 23 \\
\hline \multicolumn{2}{|l|}{ Liquid limit (\%) } & 44 \\
\hline \multicolumn{2}{|l|}{ Plastic limit (\%) } & 19 \\
\hline \multirow[t]{3}{*}{ Grain size distribution } & Sand $(\%)$ & 6 \\
\hline & Silt $(\%)$ & 62 \\
\hline & Clay $(\%)$ & 32 \\
\hline \multicolumn{2}{|l|}{ Classification (USCS) } & $\mathrm{CL}$ \\
\hline \multicolumn{2}{|c|}{ Coefficient of permeability $(\mathrm{cm} / \mathrm{s})$} & $2.7 \times 10^{-7}$ \\
\hline \multicolumn{2}{|c|}{ Cation exchange capacity (meq/100 gm) } & 1.9 \\
\hline \multicolumn{2}{|l|}{$\mathrm{pH}$} & 7.64 \\
\hline \multicolumn{2}{|l|}{ Dielectric Constant } & 16.46 \\
\hline \multicolumn{2}{|l|}{$\mathrm{pH}_{\mathrm{pzc}}$} & 7.3 \\
\hline
\end{tabular}

Value

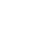




\section{List of Figures}

Fig. 1. Experimental set-up for column kinetics study

Fig. 2. Experimental set-up for large-scale column tests: (a) no slope; (b) with slope

Fig. 3. Soil permeability mixed with admixtures: (a) Bentonite, (b) Rice Husk, and (c) Fly ash

Fig. 4. Batch adsorption experimental results as a function of contact time: (a) and (b) soil contains no admixtures; (c) and (d) soil mixed with admixtures (rice husk and bentonite)

Fig. 5. $\mathrm{pH}$ and electrical conductivity versus clay (bentonite) content

Fig. 6. SEM morphology of the soil: (a) clean; (b) spiked with $\mathrm{Cr}^{6+}$; (c) mixed with rice husk admixture and spiked with $\mathrm{Cr}^{6+}$

Fig. 7. Linearized adsorption isotherm of chromium by the soil: (a) Langmuir without admixtures; (b) Langmuir with admixtures; (c) Freundlich without admixtures; (d) Freundlich with admixtures (17\% rice husk and $2 \%$ bentonite)

Fig. 8. Chromium breakthrough curves from vertical column tests (a) soil contains no admixtures (b) soil mixed with admixtures

Fig. 9. Chromium breakthrough curve from large-scale tank tests with different soil layer thicknesses (a) soil contains no admixtures (b) soil mixed with admixtures (17\% rice husk and $2 \%$ bentonite)

Fig. 10. Chromium breakthrough curve of soil without amendment from large-scale tank tests (a) no slope; (b) with slope 


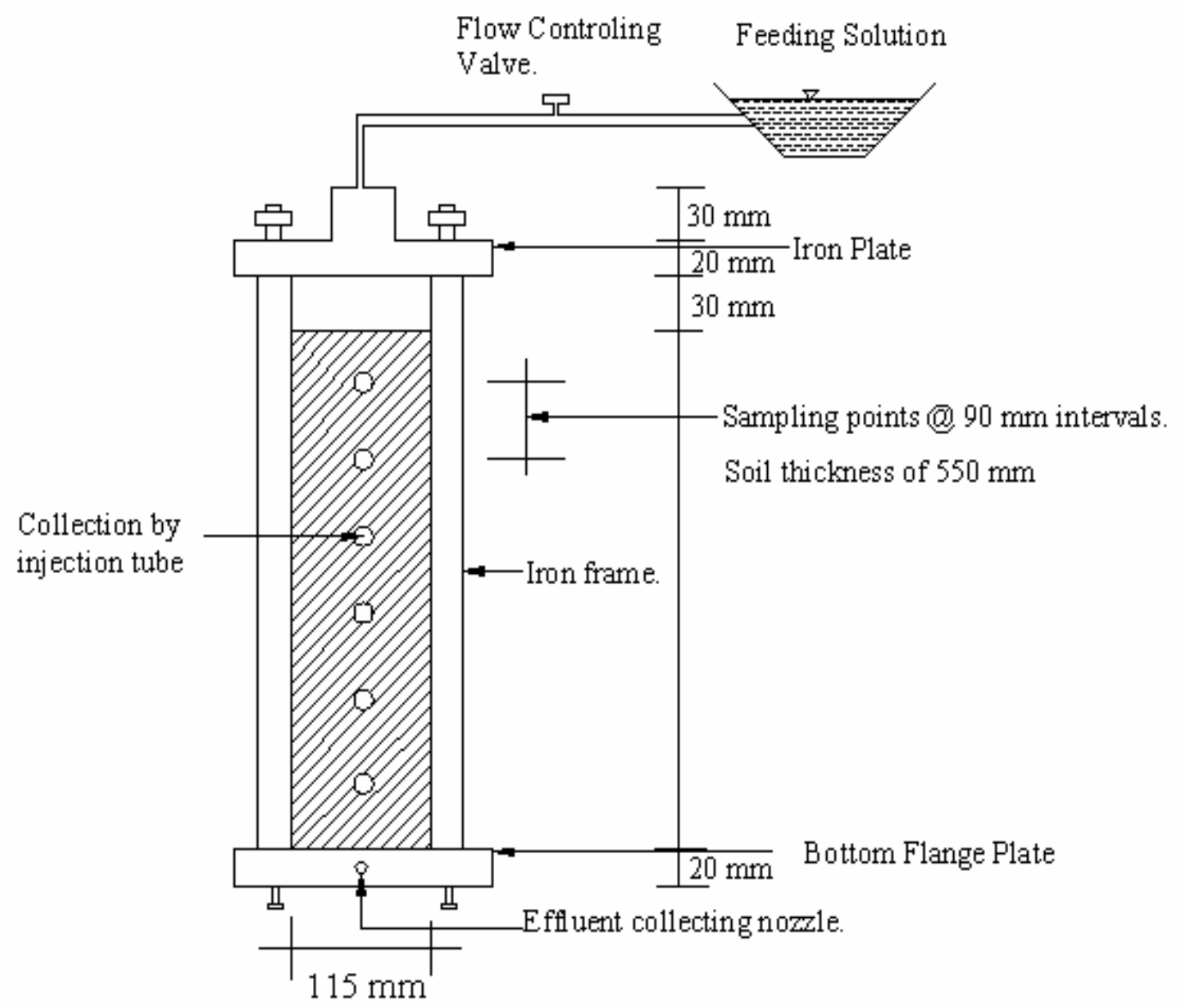

Fig. 1. Experimental set-up for column kinetics study 


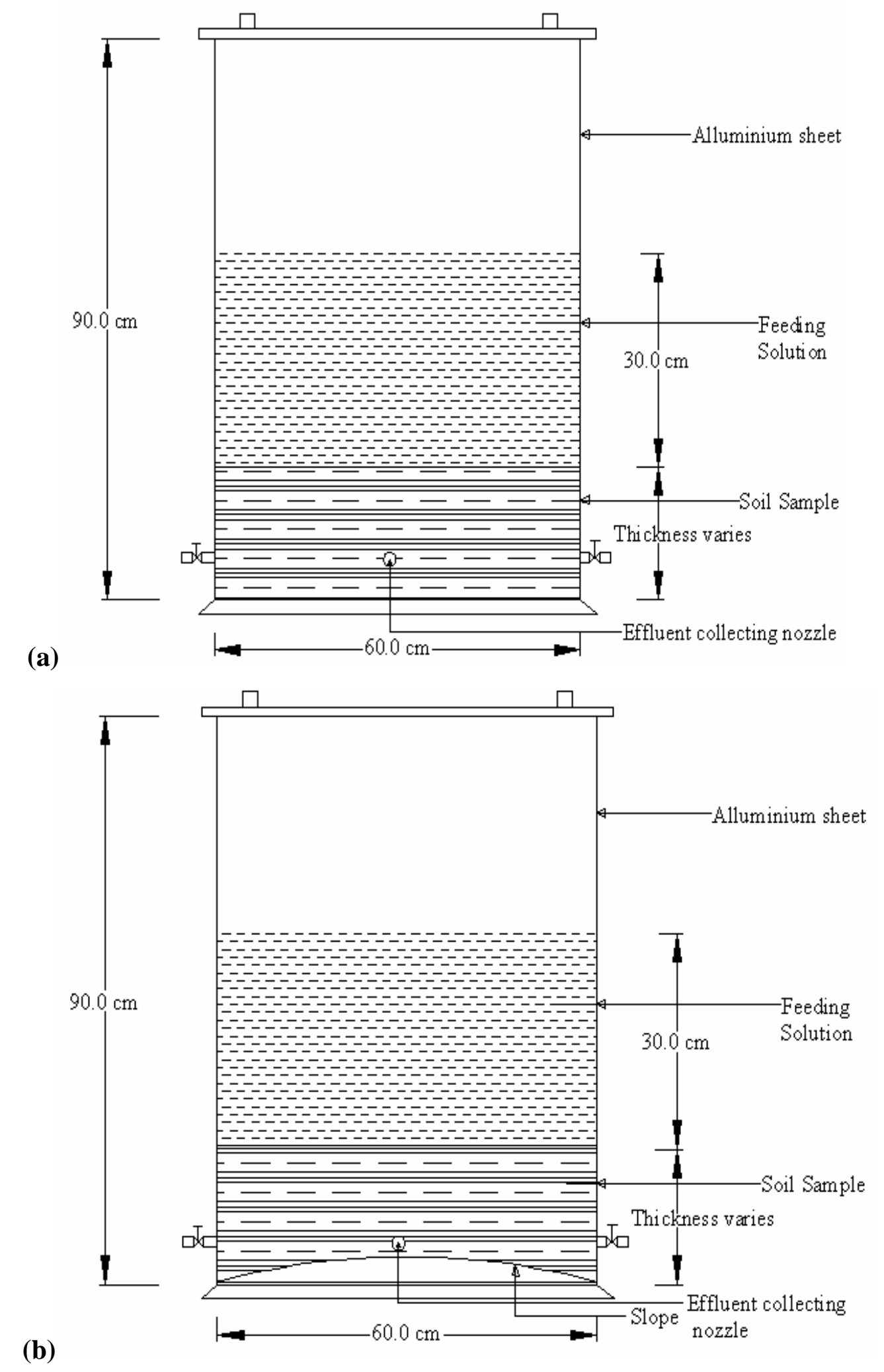

Fig. 2. Experimental set-up for large-scale column tests: (a) no slope; (b) with slope 

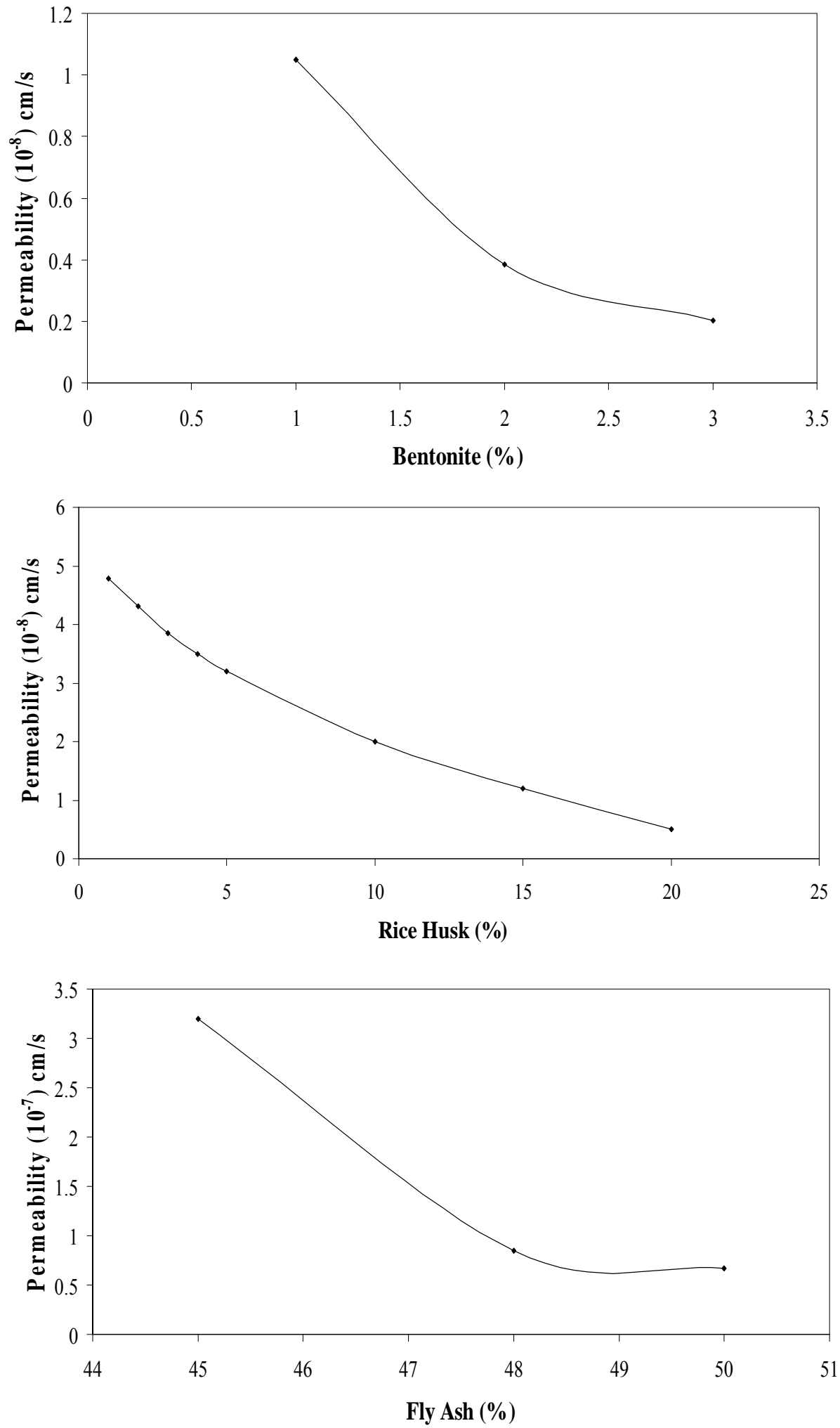

Fig. 3. Soil permeability mixed with admixtures: (a) Bentonite, (b) Rice Husk, and (c) Fly ash 

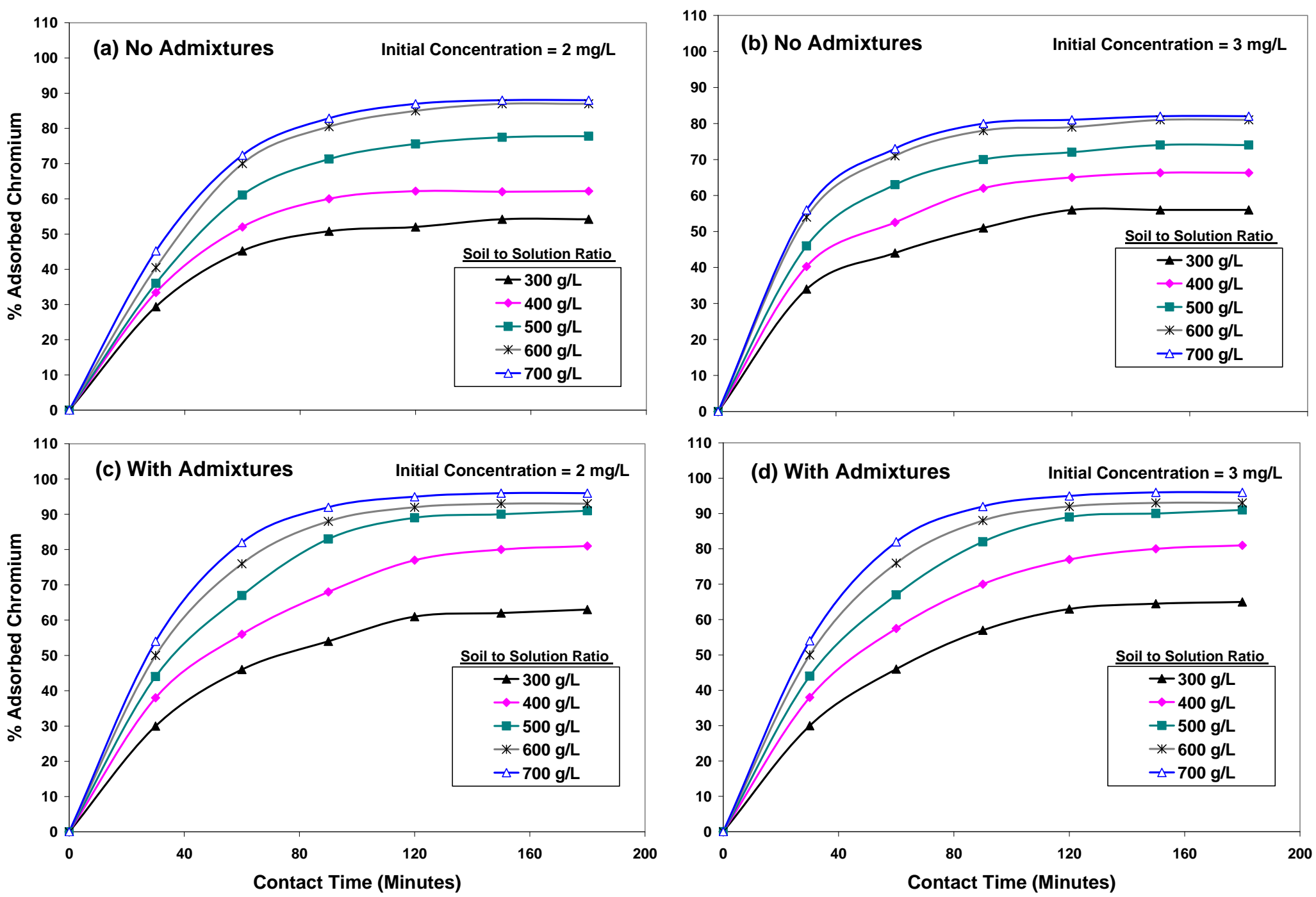

Fig. 4. Batch adsorption experimental results as a function of contact time: (a) and (b) soil contains no admixtures; (c) and (d) soil mixed with admixtures ( $17 \%$ rice husk and $2 \%$ bentonite) 

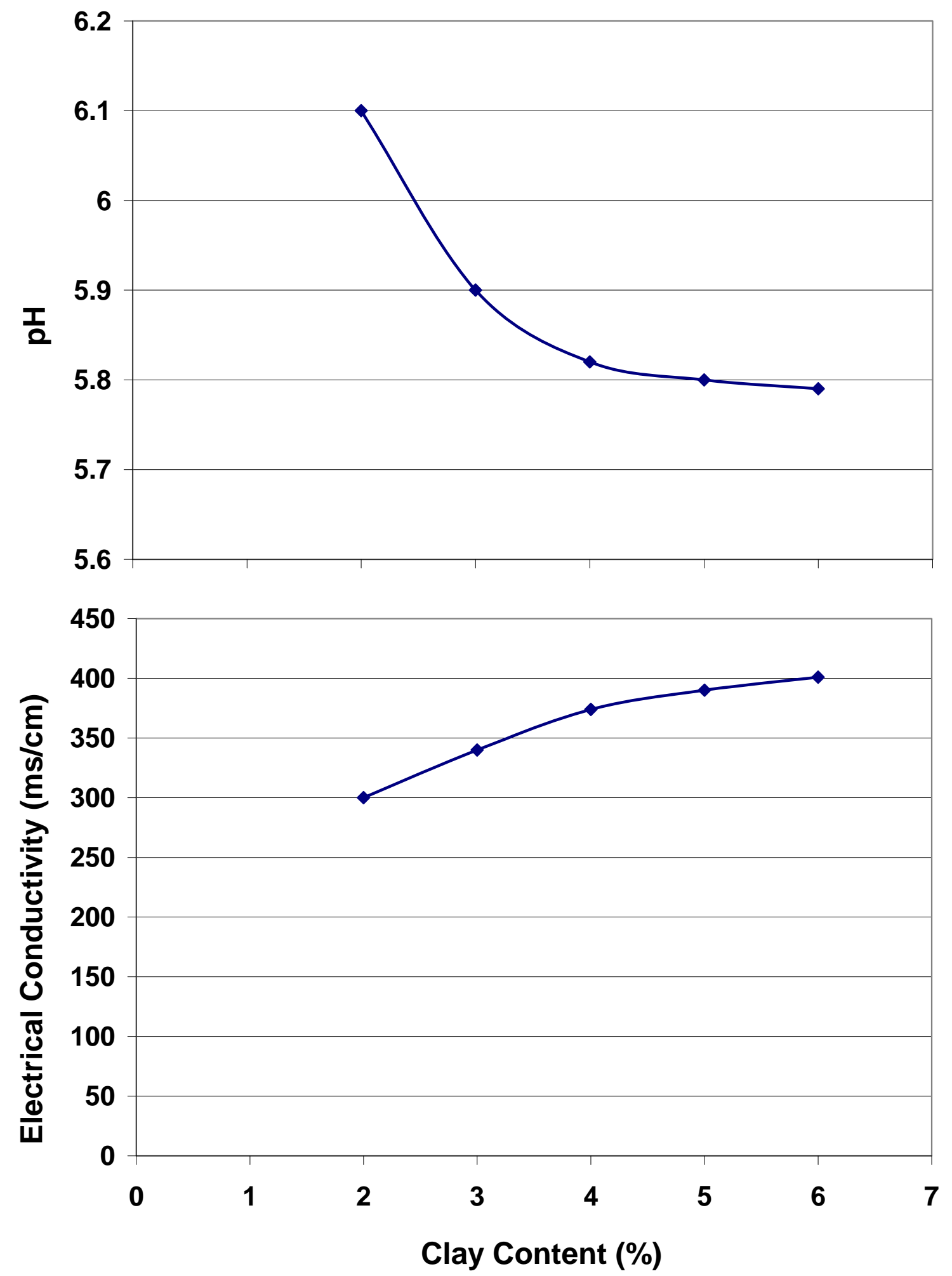

Fig. 5. $\mathrm{pH}$ and electrical conductivity versus clay (bentonite) content 
(a)

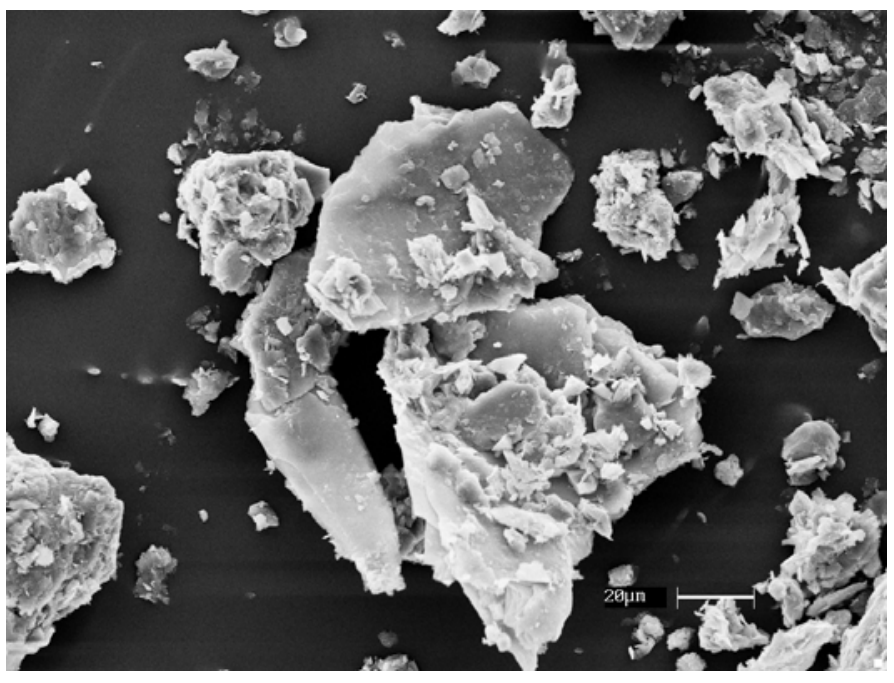

(b)
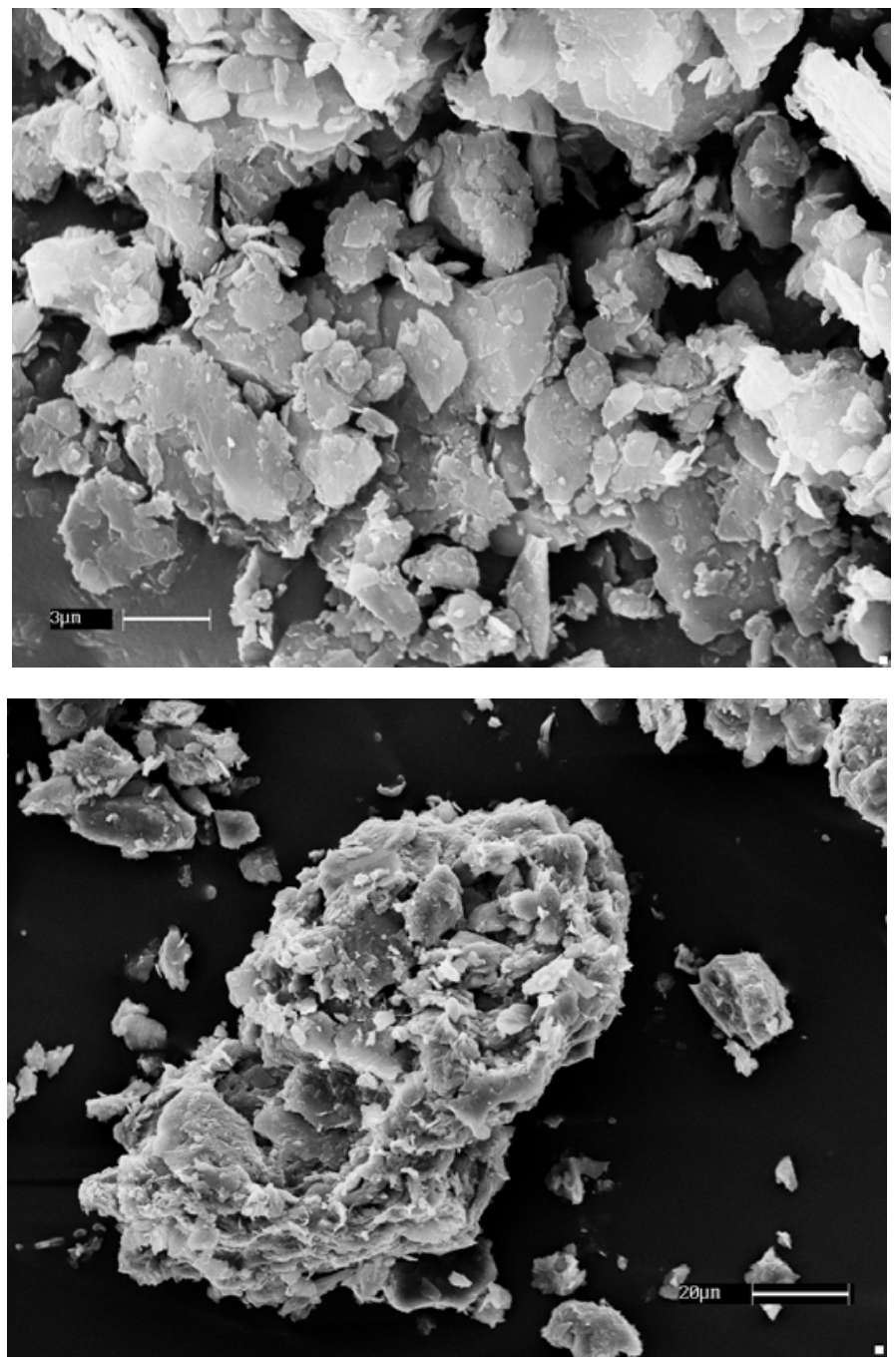

Fig. 6. SEM morphology of the soil: (a) clean; (b) spiked with $\mathrm{Cr}^{6+}$; (c) mixed with rice husk admixture and spiked with $\mathrm{Cr}^{6+}$ 

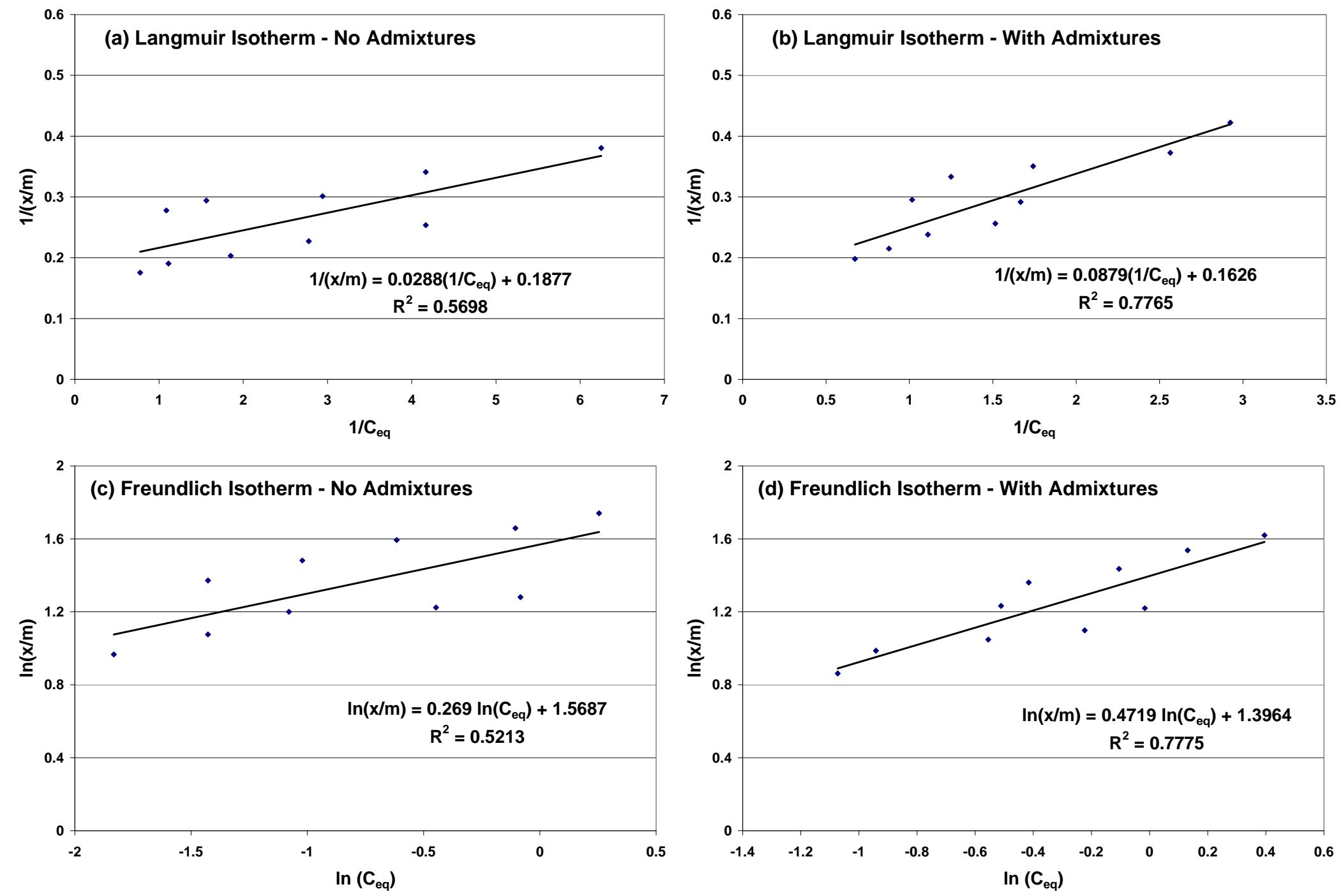

Fig. 7. Linearized adsorption isotherm of chromium by the soil: (a) Langmuir without admixtures; (b) Langmuir with admixtures (17\% rice husk and $2 \%$ bentonite); (c) Freundlich without admixtures; (d) Freundlich with admixtures (17\% rice husk and 2\% bentonite) 

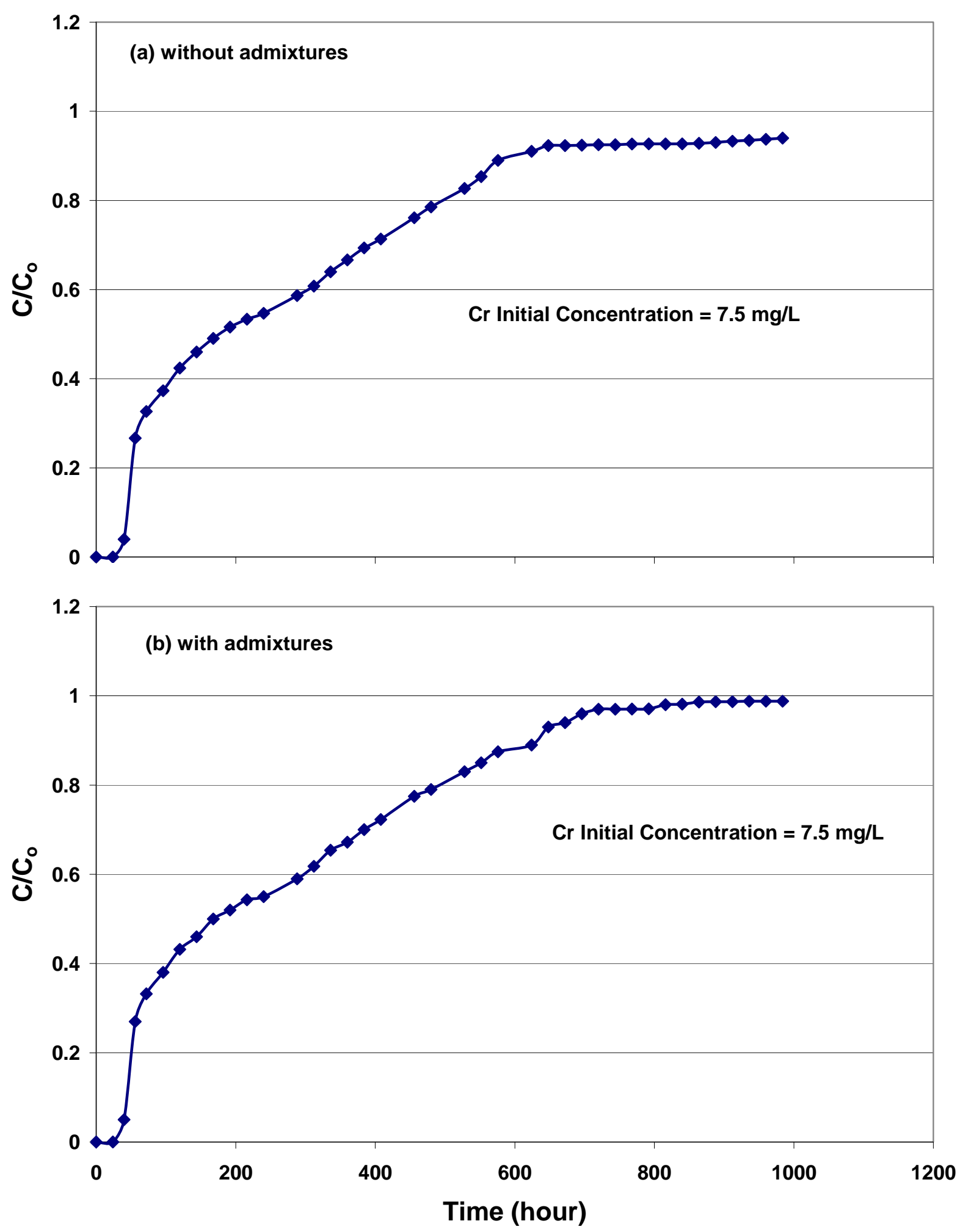

Fig. 8. Chromium breakthrough curves from vertical column tests (a) soil contains no admixtures (b) soil mixed with admixtures ( $17 \%$ rice husk and $2 \%$ bentonite) 

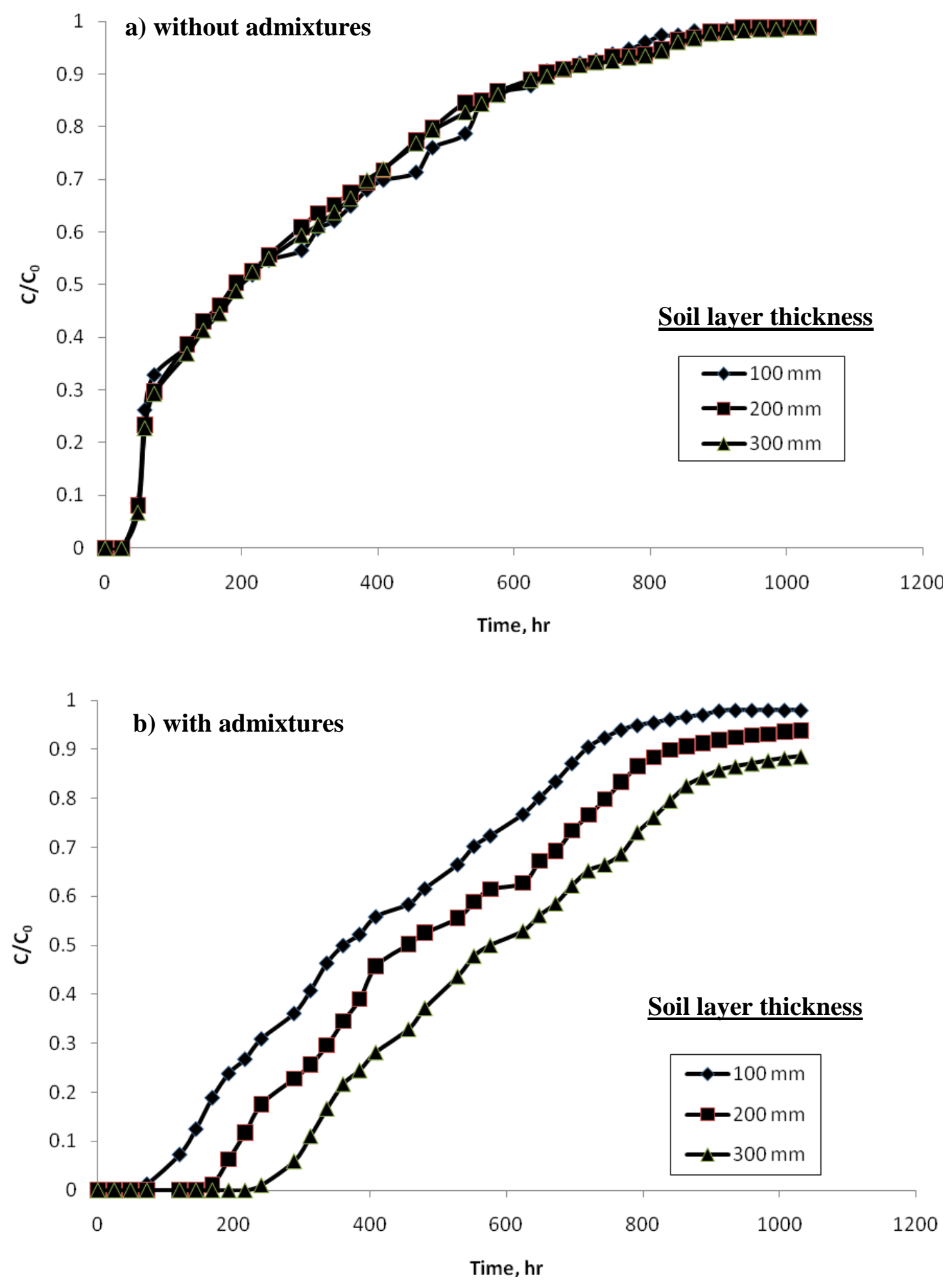

Fig. 9. Chromium breakthrough curve from large scale tank tests with different soil layer thicknesses (a) soil contains no admixtures (b) soil mixed with admixtures (17\% rice husk and $2 \%$ bentonite) 

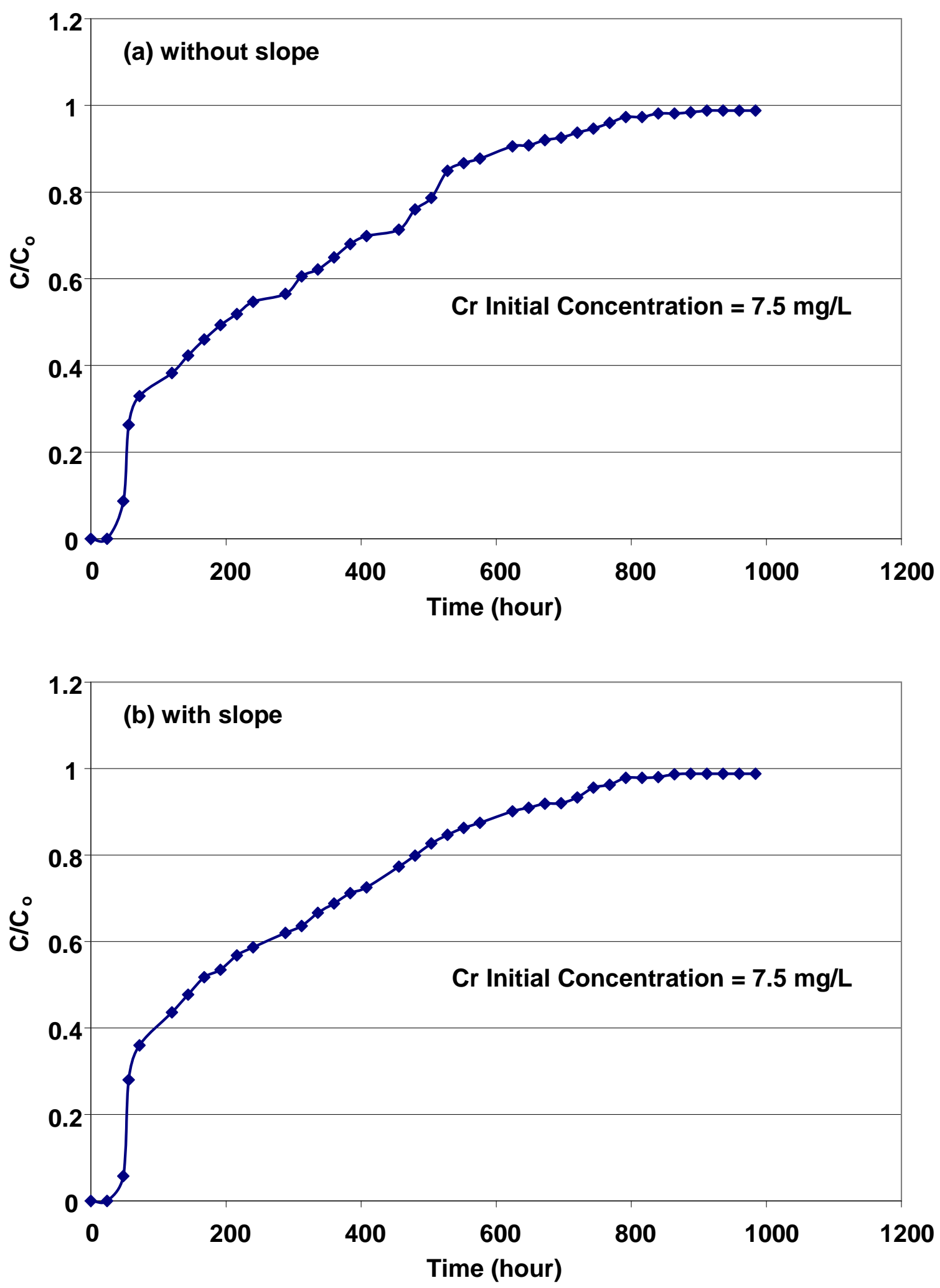

Fig. 10. Chromium breakthrough curve for field soil from large scale tank tests (a) no slope; (b) with slope 